\title{
Blue Brain boots up to mixed response
}

One of the boldest brain-modelling projects ever attempted is about to get under way in Switzerland. A team of neuroscientists plans to use a supercomputer to create a biologically realistic simulation of the neural circuits responsible for higher mental processes in humans and other mammals. But experts elsewhere are divided about its chances of success.

Most brain models focus either on large- or small-scale features. Some teams have connected huge networks of simple units to recreate brain functions such as vision, for example, whereas others have built detailed computer simulations of individual neurons. Now a team from the Swiss Federal Institute of Technology in Lausanne (EPFL) will use the IBM supercomputer Blue Gene/L in an attempt to combine both approaches.

"This is one of the most ambitious computational-neuroscience projects ever planned," says Alain Destexhe, a modeller at CNRS, France's main basic-research agency, in Gif-sur-Yvette. "Blue Gene is one of the most powerful computers ever made available to neuroscience."

The Blue Brain Project will simulate part of the neocortex, the intricately folded region on the outside of mammals' brains. The Swiss team will model a column of cells from the rat neocortex, the animal for which the most detailed data are available. Each column is just 2 millimetres high and half a millimetre in diameter, but contains some 10,000 cells connected by 5 kilometres of fibres. In both humans and rats, these columns form a basic circuitry that is repeated across the cortex and controls everything from vision and movement to planning.

"It's as if in evolution this system was cloned and duplicated in mammals - it makes up 80\% of the human brain," says Henry Markram, who leads the project at the EPFL. "The more we look at the neocortex, the more we are in awe of it."

IBM has built several Blue Gene computers for use in research (see 'Virtual Big Bangs and digital mushroom clouds'). The EPFL's version, which is worth US\$10 million and should be switched on next month, is a rack of four refrigerator-sized units, each containing more than 1,000 processors. It can process over 22 trillion operations per second. If running today, it would probably be the fourth most powerful machine in the world.

Markram will feed the simulation with information from his group's database on the

\section{"Half the research community will say this is nonsense."}

physiological and electrical properties and shapes of cortical cells, which is regarded as the most complete database of this kind in the world. Each Blue Gene processor will model one or two individual cells, which will then be connected up as in the rat cortex. The team will spend about three years testing and refining the system by comparing the results of simulations with experiments using real tissue.

Such a grand project is bound to attract critics, acknowledges Markram. "Half the research community will say this is nonsense," he says. Sure enough, when Nature put the idea to brain modellers, they hailed Blue Brain as a great leap forward in terms of the realism of simulations, but some doubted whether

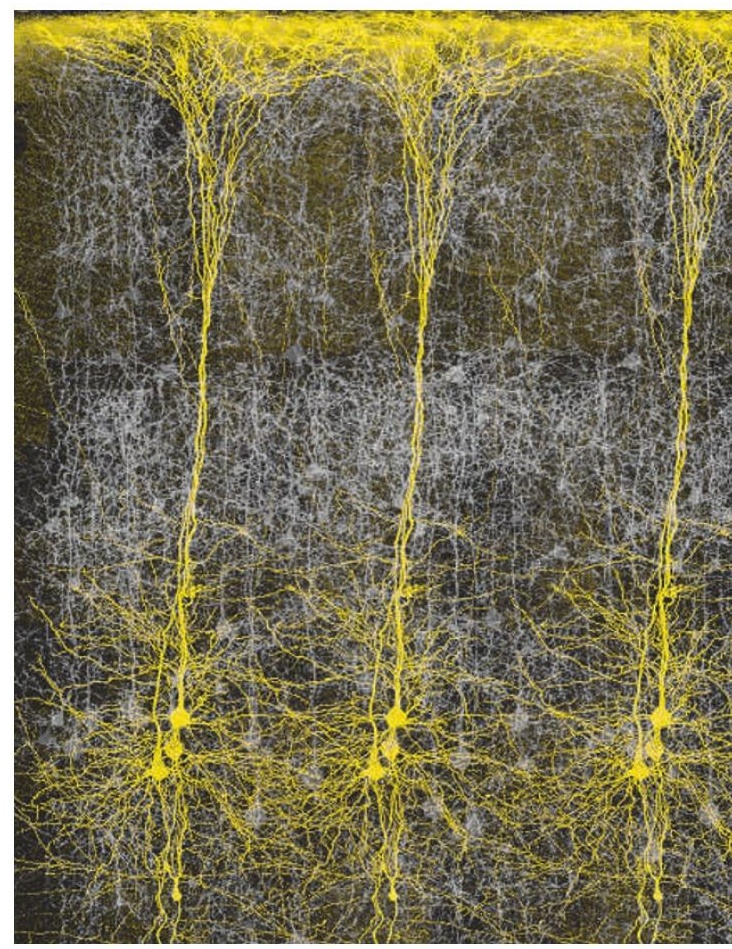

Makes you think: neuroscientists aim to create a computer model of a column of cortical cells.

Markram has enough data on the cortex to make his plan work.

"This is an ambitious project that is bound to fail," says Terry Sejnowski of the Salk Institute for Biological Studies in San Diego, California. "We are still far from understanding enough about the brain to build a detailed realistic model."

Neuroscientists say that too little is known

\section{Europe halts decisions on stem-cell patents}

\section{MUNICH}

The European Patent Office (EPO) has put patent applications involving human embryonic stem-cell technology on ice. And there are no immediate prospects for a thaw.

The EPO president, Alain Pompidou, said last week during the presentation of the organization's 2004 report that the EPO will not patent any embryonic stem-cell technology for the time being, because "there are too many ethical aspects that have not been resolved at the political level".
The EPO and the European Union have different members and are ruled by different conventions. But the EPO needs to take note of the European Union's political climate, Pompidou said. The European Commission is deciding whether to fund research on human embryonic stem cells.

Because of the moratorium, the EPO has so far received only three applications involving human embryonic cells; none has yet been approved. The office has been inundated with appeals against them, and officials are concerned that any patent granted would trigger protests similar to those that surrounded patents for genetically modified organisms. In February 2000, activists from the environmental group Greenpeace bricked up the door to the organization's Munich headquarters.

The EPO worries that it would not get political backing to defend itself against such action in the wake of a human embryonic stem-cell patent.

Many European scientists are unhappy 


\section{Virtual Big Bangs and digital mushroom clouds}

Blue Gene/Ls are bringing huge computing power to fields from cosmology to drug discovery, because they are relatively cheap and compact.

\section{WEAPONS RESEARCH}

Lawrence Livermore National Laboratory in California has the cream of the Blue Gene crop: a 64-rack machine that IBM says will be the fastest computer in the world. Due for completion this summer, the device will be used for nuclear-weapons research.

\section{RADIOASTRONOMY}

The Netherlands' Low Frequency Array radio telescope will use a four-rack Blue Gene machine based at the University of Groningen. It will analyse data from 15,000 antennas spanning an area $350 \mathrm{~km}$ in diameter.

\section{PROTEIN FOLDING}

Researchers at the University of Edinburgh, UK, are using a single-rack Blue Gene machine, capable of 6 trillion operations per second, to simulate protein folding and fluid mixing.

\section{CLIMATE RESEARCH}

A single-rack Blue Gene is being shared by the National Center for Atmospheric Research and the University of Colorado, which will run simulations of ocean, weather and climate behaviour.

\section{COSMOLOGY}

A team at the San Diego Supercomputing Center is using a single-rack Blue Gene to run Enzo - the centre's software that simulates how galaxies evolved from the Big Bang. The simulation, which has already predicted how the first stars formed, produced around 30,000 gigabytes of data on a typical recent run.

\section{DRUG DEVELOPMENT}

Japan's National Institute of Advanced Industrial Science and Technology is using its four-rack device to boost drug development. Researchers there hope to shed light on how drugs interact with their targets in the body. about the structure of the network connecting cortical cells, for example. They add that a truly realistic model would have to incorporate molecular activity in the regions where neurons connect, a level of detail that is currently beyond the Blue Brain Project.

Markram agrees that more data are needed, especially from the bottom section of the sixlayer cortical column, but says that work to remedy this will be done while the machine is being tested. Once the model is fully functional, researchers will be able to play with it, tweaking the numbers of different types of neuron, for example, or altering the levels of certain neurotransmitters, to see how such changes affect larger-scale brain activity.

The machine could also probe conditions in which cortical circuitry seems to malfunction.
For example, some symptoms of autism can be recreated in rodents by giving thalidomide during pregnancy. The thalidomide causes changes in the cortex cells that could be mimicked on Blue Brain, says Markram.

In the long-term, Markram has a grander plan that will raise eyebrows among even his most supportive peers. Within ten years, he predicts, column models could be duplicated and connected to create simulations of the whole cortex and eventually the whole brain.

Fred Wolf, a computational neuroscientist at the Max Planck Institute for Dynamics and Self-Organisation in Göttingen, Germany, is enthusiastic about the idea. But he adds: "Don't expect to see whole-brain simulations any time soon."

Jim Giles with the delay. Patent offices in the United States and many Asian counties, including South Korea, allow inventions involving human embryonic stem cells to be patented. "The EPO underestimates the economic damage this attitude will cause in Europe," warns Oliver Brüstle of Germany's Institute for Reconstructive Neurobiology, one of the three applicants.

One hope remains for Brüstle and his colleagues. One of the applications, rejected last year, is making its way through the
EPO's appeals procedure. It is being considered by the technical appeals board, which will give its judgement in October.

Siobhán Yeats, director for biotechnology at the EPO, says that if the board cannot settle the case on technical grounds, it may pass it on to the EPO's highest appeals board, the Enlarged Board of Appeal. The Enlarged Board rules on the fundamental patentability of inventions, and so could set a precedent.

Sonja Schubert 